\title{
Wait times for diagnostic colonoscopy among outpatients with colorectal cancer: A comparison with Canadian Association of Gastroenterology targets
}

\author{
Michael Sai Lai Sey MD FRCPC ${ }^{1}$, Jamie Gregor MD FRCPC ${ }^{1}$, Paul Adams MD FRCPC ${ }^{1}$, Nitin Khanna MD FRCPC ${ }^{1}$, \\ Chris Vinden MD FRCSC ${ }^{2}$, David Driman MBChB FRCPC ${ }^{3}$, Nilesh Chande MD FRCPC ${ }^{1}$
}

\begin{abstract}
MSL Sey, J Gregor, P Adams, et al. Wait times for diagnostic colonoscopy among outpatients with colorectal cancer: A comparison with Canadian Association of Gastroenterology targets. Can J Gastroenterol 2012;26(12):894-896.
\end{abstract}

BACKGROUND: Timely access to colonoscopy is a nationally recognized issue in Canada, with previous studies documenting significant wait times for a variety of indications. However, specific wait times for colonoscopy among patients diagnosed with colorectal cancer remain unknown.

METHODS: A review of all outpatient cases of colorectal cancer diagnosed at colonoscopy in London, Ontario, in 2010 was performed. Wait times from the date of referral to colonoscopy were reviewed and compared with maximal wait times established by the Canadian Association of Gastroenterology (CAG) stratified according to indication. Cancer stage at the time of diagnosis was compared with colonoscopy wait times.

RESULTS: A total of 106 colorectal cancer patients meeting the inclusion and exclusion criteria were included in the study. Forty-six per cent of patients waited longer than CAG targets, with a mean $( \pm$ SD) wait time of $79 \pm 101$ days. Higher cancer stage was associated with shorter wait time, likely as a result of triaging.

CONCLUSION: Long wait times for diagnostic colonoscopy among patients with colorectal cancer remain an issue, with a significant proportion of cases not meeting maximal CAG wait time targets.

Key Words: Colonoscopy; Colorectal cancer; Wait times
Olorectal cancer is the second leading cause of cancer-related mortality in Canada. An estimated 22,200 new cases were diagnosed in 2011, with 8900 deaths (1). Phase III randomized clinical trials are currently underway to determine the efficacy of screening colonoscopies for reducing colorectal cancer-related mortality (NCT00906997, NCT00883792 and NCT01239082), although the results will not be available for at least a decade. In the interim, multiple observational studies have already documented a reduction in colorectal cancer mortality associated with colonoscopy $(2-5)$. However, timely access to specialist care is a challenge in Canada. In the National Health Services Access Survey (6), one in five Canadians experienced difficulty accessing specialist care, resulting in excess worry, anxiety and stress. A nationwide practice audit of wait time for endoscopy (7) revealed a median and 75th percentile wait time of 91 and 203 days, respectively.

In response to these challenges, the Canadian Association of Gastroenterology (CAG) developed a consensus statement for maximal acceptable wait times for digestive health care (8). The consensus statement addressed maximal wait times for consultation or procedure for a variety of indications (Table 1). However, two follow-up studies after the publication of the consensus statement continued to reveal
Les temps d'attente avant la coloscopie diagnostique chez les patients ambulatoires atteints d'un cancer colorectal : une comparaison avec les cibles de l'Association canadienne de gastroentérologie

HISTORIQUE : L'accès rapide à la coloscopie est un problème reconnu partout au Canada, des études antérieures étayant d'importants temps d'attente pour diverses indications. Cependant, on ne connaît pas les temps d'attente avant la coloscopie chez les patients obtenant un diagnostic de cancer colorectal.

MÉTHODOLOGIE : Les chercheurs ont analysé tous les cas de patients ambulatoires atteints d'un cancer colorectal diagnostiqué au moment de la coloscopie à London, en Ontario, en 2010. Ils ont examiné les temps d'attente à compter de la date d'aiguillage vers la coloscopie et les ont comparés avec les temps d'attente maximaux établis par l'Association canadienne de gastroentérologie (ACG), stratifiés conformément aux indications. Le stade de cancer au moment du diagnostic était comparé au temps d'attente de la coloscopie.

RÉSULTATS : Au total, 106 patients atteints d'un cancer colorectal qui respectaient les critères d'inclusion et d'exclusion ont participé à l'étude. Quarante-six pour cent des patients ont attendu plus longtemps que les cibles de l'ACG, pour un temps d'attente moyen $( \pm E ́ T)$ de $79 \pm 101$ jours. Un stade plus avancé de cancer s'associait à un temps d'attente plus court, probablement en raison du triage.

CONCLUSION : De longs temps d'attente demeurent problématiques chez les patients atteints d'un cancer colorectal qui doivent subir une coloscopie diagnostique, car une forte proportion des cas ne respecte pas les cibles maximales de temps d'attente de l'ACG.

\section{TABLE 1}

Canadian Association of Gastroenterology maximal wait times for selected referral indications

\begin{tabular}{lc}
\hline Indication & Maximal wait time \\
\hline High likelihood of cancer based on exam or imaging & $<2$ weeks \\
Bright red blood per rectum & $<2$ months \\
Documented iron deficiency anemia & $<2$ months \\
One or more positive fecal occult blood test(s) & $<2$ months \\
New-onset change in bowel habit & $<2$ months \\
Screening colonoscopy & $<6$ months \\
\hline
\end{tabular}

Data from reference 8. exam Examination

long wait times $(9,10)$. Although these studies highlight the long wait times patients endure for general digestive health referrals, the direct impact of diagnostic delays among patients with a time-sensitive diagnosis, such as colorectal cancer, remains unknown. The primary objective of the present study was to determine the wait time for diagnostic colonoscopy among patients with colorectal cancer. The secondary objective was to determine the association between wait times and cancer stage.

\footnotetext{
${ }^{1}$ Department of Medicine, Division of Gastroenterology; ${ }^{2}$ Department of Surgery; ${ }^{3}$ Department of Pathology, University of Western Ontario, London, Ontario

Correspondence: Dr Michael Sai Lai Sey, London Health Sciences Centre - Victoria Campus, 800 Commissioners Road, London, Ontario N6A 5W9.

Telephone 519-667-6582 ext 5, fax 519-667-6820, e-mail msey2@uwo.ca

Received for publication February 4, 2012. Accepted May 2, 2012
} 


\section{METHODS}

Study population

A review of all outpatient cases of colorectal cancer diagnosed at colonoscopy between January 1 and December 31, 2010, in London, Ontario, was conducted. The city is served by the London Health Sciences Centre (University and Victoria Campuses) and St Joseph's Health Care, which are tertiary care hospitals affiliated with the University of Western Ontario, serving a catchment area of 350,000 for colonoscopy and a tertiary referral population of 1,000,000. A small, private, part-time outpatient endoscopy clinic was active during part of the study period but did not detect any cases of colorectal cancer. The study was approved by the University of Western Ontario Research Ethics Board.

All cases of histologically confirmed colorectal cancer diagnosed at colonoscopy during the study period were retrieved from the citywide pathology database. Only new referrals to the endoscopist (15 gastroenterologists, two internists and 11 general surgeons) were included in the study. Exclusion criteria included patients who were not a new referral to the endoscopist, inpatient procedures, history of colorectal cancer, familial cancer syndrome and inflammatory bowel disease.

\section{Outcomes}

Demographic data (age, sex), referral date and indication (based on faxed referral form), consultation and endoscopy date, and cancer stage (American Joint Committee on Cancer: tumour, node, metastasis staging) (11) were determined. Referral indications were sorted into categories used in the CAG consensus statement (Table 1). Wait time was defined as the delay between when the referral was received and when the procedure was performed.

There are no specific citywide triage guidelines in London, and triage is left to the discretion of the individual endoscopists' office. There are a limited number of urgent outpatient endoscopy slots available weekly at each hospital.

Wait times were stratified according to CAG referral indications and compared with targets to determine the percentage of patients exceeding suggested maximal wait times. Mean, median and range of wait times were also determined. Cancer stage was compared with wait times for colonoscopy.

\section{Statistical analysis}

Descriptive analysis was completed for the study sample (mean, median, range and SD). The difference in the number of patients exceeding target wait times for each indication and according to cancer stage was analyzed using Fisher's exact test. Differences in mean wait time as a function of cancer stage was analyzed using ANOVA. $\mathrm{P}<0.05$ was considered to be statistically significant.

\section{RESULTS}

A total of 185 patients were endoscopically diagnosed with colorectal cancer in 2010. Seventy-nine cases were excluded (27 were not new referrals, 33 diagnosed as inpatients, 12 had a history of colorectal cancer, one had a history of inflammatory bowel disease and six had insufficient information regarding referral date/indication). One patient, who was diagnosed as an inpatient, was awaiting outpatient
TABLE 2

Baseline patient characteristics

\begin{tabular}{lc}
\hline Patients, $\mathrm{n}$ & 106 \\
Age, years, mean \pm SD & $68 \pm 12$ \\
Female sex & $49(46)$ \\
Indication & \\
High likelihood of cancer based on examination or imaging & $20(19)$ \\
Bright red blood per rectum & $36(34)$ \\
Documented iron deficiency anemia & $23(22)$ \\
One or more positive fecal occult blood test & $11(10)$ \\
New onset change in bowel habit & $6(6)$ \\
Screening colonoscopy & $10(9)$ \\
Cancer stage & \\
1 & $21(20)$ \\
2 & $32(30)$ \\
3 & $35(33)$ \\
4 & $9(9)$ \\
Insufficient information for staging & $9(9)$ \\
Cancer site & \\
Colon & $59(56)$ \\
Rectum & $47(44)$ \\
\hline
\end{tabular}

Data presented as $n$ (\%) unless otherwise indicated

colonoscopy when he was admitted to hospital with hematochezia and underwent an inpatient colonoscopy instead. A total of 106 cases were included in the study (Table 2). Seventy-nine per cent of patients had consultation and underwent colonoscopy on the same day.

Forty-six per cent of patients with colorectal cancer exceeded wait time targets, with no significant differences among referral indications $(\mathrm{P}=0.99)$ (Table 3). The overall mean $( \pm \mathrm{SD})$ wait time for all indications was $79 \pm 101$ days. Three patients delayed their colonoscopy date due to personal reasons.

Patients with stage I colorectal cancer had the longest mean wait time, which decreased with increasing cancer stage $(\mathrm{P}=0.003)$ (Figure 1). There were no significant differences in the percentage of patients exceeding wait-time targets for each cancer stage $(\mathrm{P}=0.30)$ (Figure 2).

\section{DISCUSSION}

Outpatients in London, Ontario, experience long delays for diagnostic colonoscopy for colorectal cancer, with $46 \%$ of cases exceeding CAG targets. Although mean and median wait times appear to approximate CAG targets, they should be interpreted with caution because a patient with a short wait time should not compensate for a patient with a long wait time. This is reflected in the wide range of wait times, with some patients having very short waits if urgent endoscopy slots are available. For this reason, we focused our study on the number of patients who exceeded CAG wait time targets as a more important representation of total wait times.

Among patients with stage 1 colorectal cancer, the mean wait time was in excess of 150 days. It is possible that earlier colonoscopy with

\section{TABLE 3}

Wait times for colonoscopy according to indication and all indications combined

\begin{tabular}{|c|c|c|c|c|}
\hline \multirow[b]{2}{*}{ Indication } & \multirow{2}{*}{$\begin{array}{l}\text { Cases exceeding } \\
\text { CAG target, } \mathrm{n}(\%)\end{array}$} & \multicolumn{3}{|c|}{ Wait time, days } \\
\hline & & Mean \pm SD & Median & Range \\
\hline High likelihood of cancer based on examination or imaging & $10(50)$ & $23 \pm 25$ & 15 & $4-96$ \\
\hline Bright red blood per rectum & $16(44)$ & $77 \pm 85$ & 40 & $3-364$ \\
\hline One or more positive fecal occult blood test(s) & $5(46)$ & $67 \pm 49$ & 51 & $7-134$ \\
\hline New-onset change in bowel habit & $3(50)$ & $42 \pm 40$ & 44 & $1-90$ \\
\hline
\end{tabular}

CAG Canadian Association of Gastroenterology 


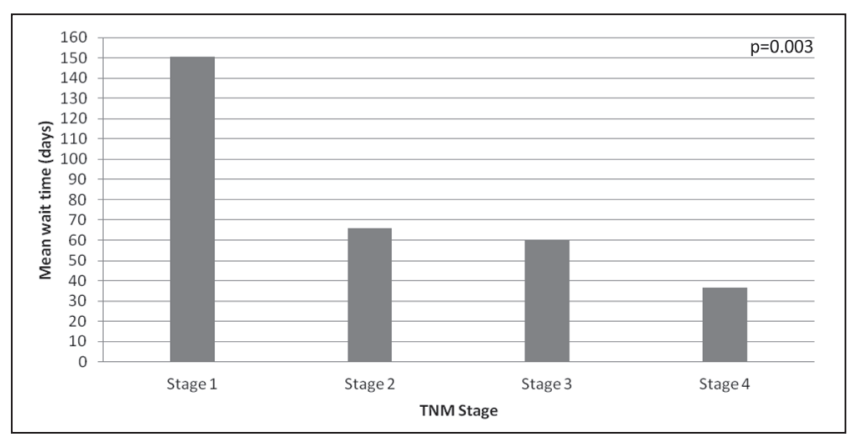

Figure 1) Mean wait time versus cancer stage. TNM Tumour, node, metastasis

polypectomy in this subgroup before progression from high-grade dysplasia to invasive adenocarcinoma could be curative and avoided the need for surgery.

Since the publication of the CAG consensus statement, several studies have reported on wait times for digestive health care in Canada. In a single-centre study from Queen's University (Kingston, Ontario), Yu et al (10) reported a mean wait time of 229 days, with $78.6 \%$ of cases not meeting CAG targets. In a nationwide survey, Leddin et al (9) reported a mean wait time of 155 days. However, these studies only addressed wait times for general digestive health referrals. Thus, the wait times for those with a time-sensitive diagnosis, such as colorectal cancer, remain unknown. Singh et al (12) partially addressed this issue in a population-based study of wait times from presentation to treatment for colorectal cancer in Manitoba. They reported a colonoscopy wait time of 54 days, which was comparable with our results. However, multiple assumptions had to be made because the data were derived from health registries. Although not directly comparable, the sum of these studies with ours suggests that long wait times continue to be a challenge in Canada.

Long wait times directly impact patients and contribute to anxiety, lost time from work and social functioning (13). Of greater concern is the potential that diagnostic delays enable the development of more advanced cancers. However, our study demonstrated an inverse relationship with stage I cancer having the longest wait time. This is likely due to triaging of referrals because advanced cancers often have more urgent presentations. At its root, the CAG consensus statement is itself a triaging tool. Other studies attempting to demonstrate a relationship between diagnostic delay and cancer stage have also produced conflicting results (14-16).

One limitation of our study was its single-city design, which only reflects wait times in London, Ontario. However, because a national database on colonoscopy wait times does not exist, studies such as ours provide insight into this important issue. Another limitation of our study was its retrospective design, which although subject to more bias, enables the most thorough collection of cases. Our selection of hard outcomes, such as the presence of cancer and wait times, also limits bias in our study. Finally, $44 \%$ of our cases were rectal cancers, which is higher than expected and may represent a referral bias in our study population.

Long wait times for diagnostic colonoscopy among patients with colorectal cancer have persisted since the publication of target wait times. Strategies to enable timely access to colonoscopy for patients suspected of having colorectal cancer are needed.

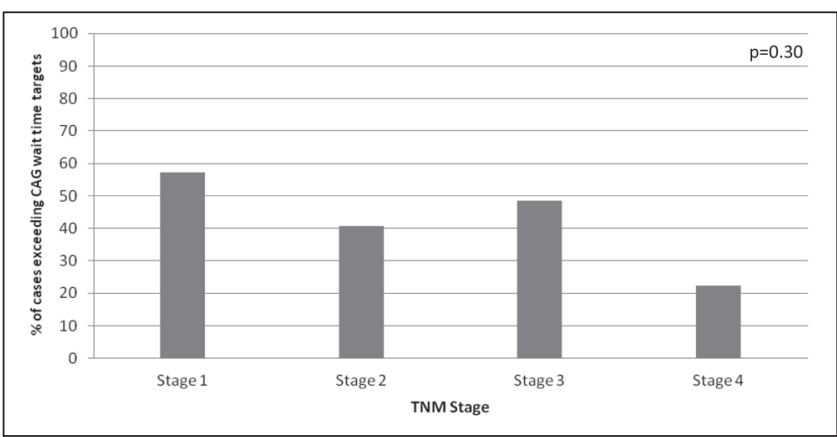

Figure 2) Adherence with Canadian Association of Gastroenterology (CAG) wait time targets according to cancer stage. TNM Tumour, node, metastasis

\section{REFERENCES}

1. Canadian Cancer Society's Steering Committee on Cancer Statistics. Canadian Cancer Statistics 2011. Toronto: Canadian Cancer Society; 2011.

2. Baxter NN, Goldwasser MA, Paszat LF, et al. Association of colonoscopy and death from colorectal cancer. Ann Intern Med 2009;150:1-8.

3. Kahi CJ, Imperiale TF, Juliar BE, Rex DK. Effect of screening colonoscopy on colorectal cancer incidence and mortality. Clin Gastroenterol Hepatol 2009; 7:770-5.

4. Winawer SJ, Zauber AG, Ho MN, et al. Prevention of colorectal cancer by colonoscopic polypectomy. N Engl J Med 1993;329:1977-81.

5. Rabeneck L, Paszat LF, Saskin R, Stukel TA. Association between colonoscopy rates and colorectal cancer mortality. Am J Gastroenterol 2010;105:1627-32.

6. Sanmartin C, Gendron F, Berthelot JM, Murphy K. Access to Health Care Services in Canada, 2003. Ottawa: Statistics Canada; 2004.

7. Armstrong D, Barkun A, Chen Y, et al. Access to specialist care in Canada: The practice audit in gastroenterology (PAGE) wait times program. Can J Gastroenterol 2008;22:155-60.

8. Paterson WG, Depew WT, Pare P, et al. Canadian consensus on medically acceptable wait times for digestive health care. Can J Gastroenterol 2006;20:411-23.

9. Leddin D, Bridges RJ, Morgan DG, et al. Survey of access to gastroenterology in Canada: The SAGE wait times program. Can J Gastroenterol 2010;24:20-5.

10. Yu D, Hopman WM, Paterson WG. Wait times for endoscopic evaluation at a Canadian tertiary care centre: Comparison with Canadian Association of Gastroenterology targets. Can J Gastroenterol 2008;22:621-6.

11. American Joint Committee on Cancer. AJCC Cancer Staging Manual, 7th edition. Chicago: Springer New York; 2010.

12. Singh $\mathrm{H}$, De Coster C, Shu E, et al. Wait times from presentation to treatment for colorectal cancer: A population-based study. Can J Gastroenterol 2010;24:33-9.

13. Paterson WG, Barkun AN, Hopman WM, et al. Wait times for gastroenterology consultation in Canada: The patients' perspective. Can J Gastroenterol 2010;24:28-32.

14. Wattacheril J, Kramer JR, Richardson P, et al. Lagtimes in diagnosis and treatment of colorectal cancer: Determinants and association with cancer stage and survival. Aliment Pharmacol Ther 2008;28:1166-74.

15. Langenbach MR, Schmidt J, Neumann J, Zirngibl H. Delay in treatment of colorectal cancer: Multifactorial problem. World J Surg 2003;27:304-8.

16. Arbman G, Nilsson E, Storgren-Fordell V, Sjodahl R. A short diagnostic delay is more important for rectal cancer than for colonic cancer. Eur J Surg 1996;162:899-904. 


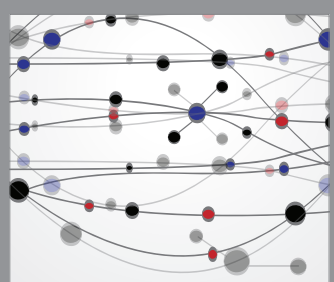

The Scientific World Journal
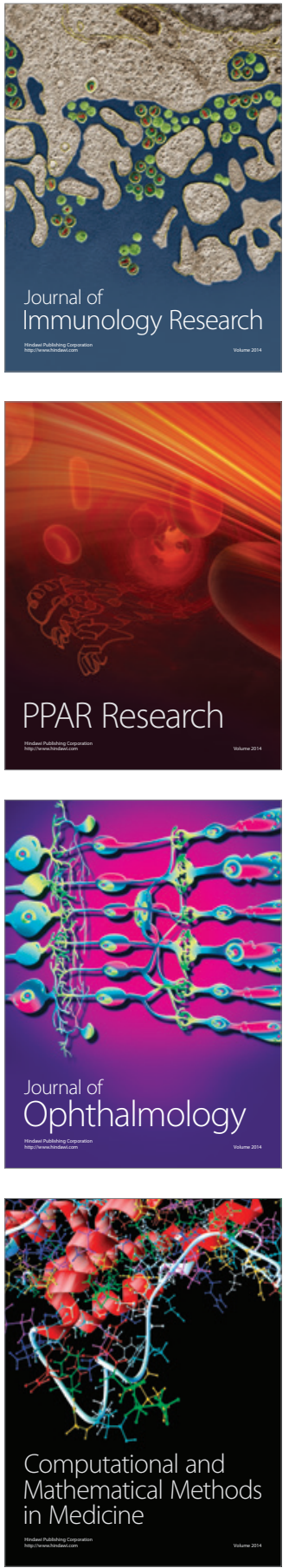

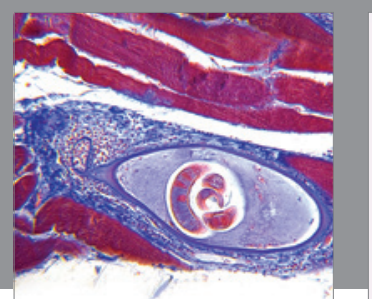

Gastroenterology Research and Practice

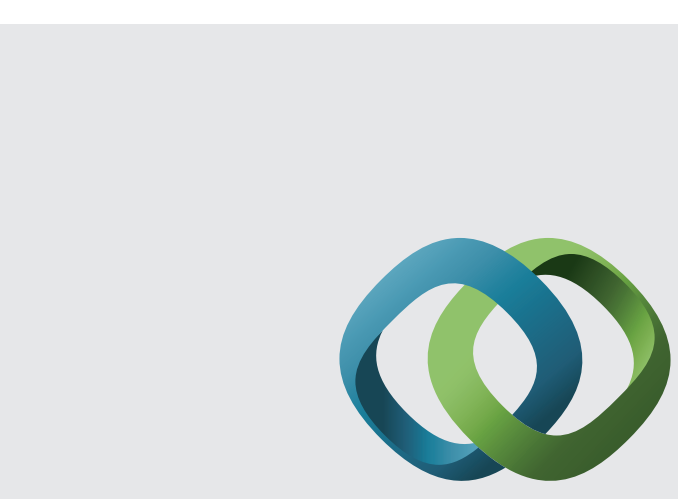

\section{Hindawi}

Submit your manuscripts at

http://www.hindawi.com
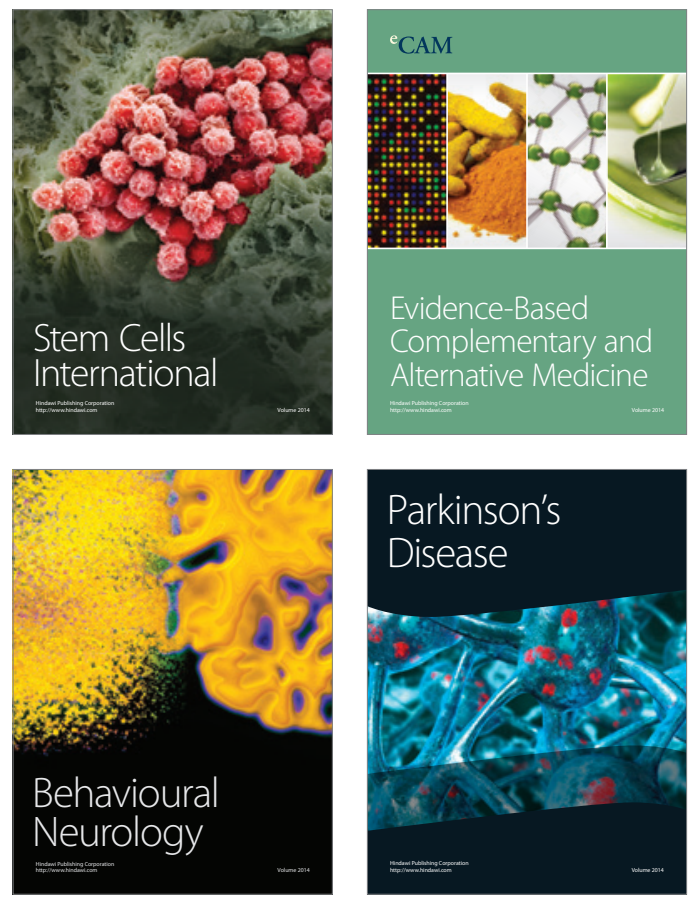
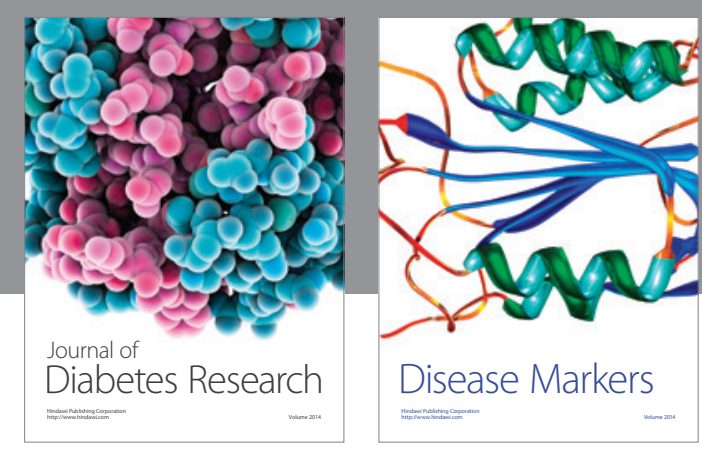

Disease Markers
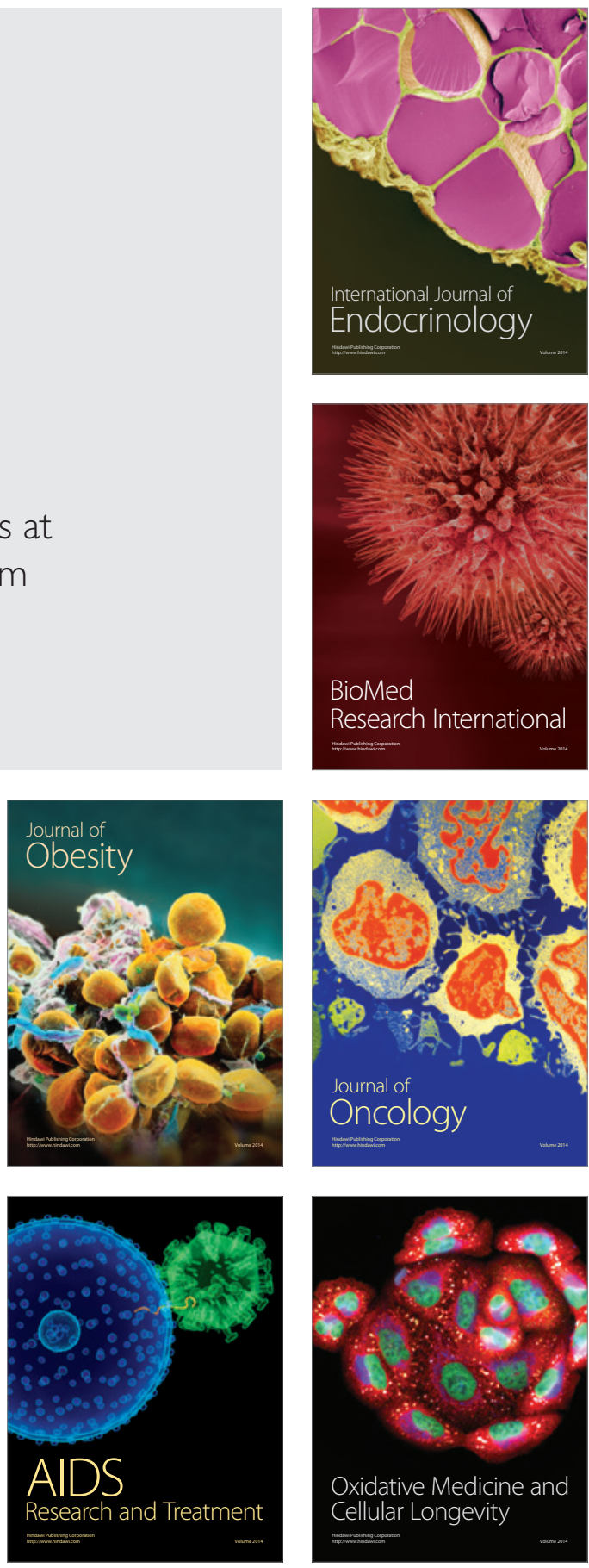